\title{
Em torno das origens da Guiana Francesa: dos primórdios ao século XIX
}

\author{
luri Cavlak ${ }^{1}$
}

1 Doutor em História pela Unesp de Assis. Professor do Colegiado de História e do Programa de Mestrado em Desenvolvimento Regional da UNIFAP. Coordenador do Mestrado em Ensino de História, núcleo local da UNIFAP, Brasil. E-mail: iuricavlak@yahoo.com.br

RESUM 0: Esse texto visa uma breve análise da história da Guiana Francesa, do início de sua colonização até a invasão luso-paraense em 1809. Baseado na historiografia pertinente, busco descrever os primeiros movimentos dos franceses nessas terras, os avanços e dificuldades que resultaram no estabelecimento definitivo da colônia, tendo em vista a história da Guiana Portuguesa (atual Amapá), da Guiana Inglesa (atual Guiana) e da Guiana Holandesa (atual Suriname). Entendo que, embora semelhante, cada uma dessas histórias guarda importantes particularidades. No caso da Guiana Francesa, chama atenção a perda de domínios franceses no Brasil, como no Rio de Janeiro (França Antártica) e no Maranhão (França Equinocial) como fortes motivos para escolha desse local, bem como a subsequente dificuldade de povoamento, ilustrada pela tragédia de Kourou.

Palavras-chave: História, Política, Guiana Francesa, Amapá.

Around the origins of French Guiana: from de beginning to XIX century.

ABSTRACT: This text aims a short analysis about the history of French Guiana, from the beginning of its colonization until the luso-parense invasion in 1809. Based on the relevant historiography, I search to describe the first movements of the French people in this lands, the advances and difficulties that resulted in the colonial definitive settlement, regarding the history of Portuguese Guiana (Amapá), the British Guiana (currently Guiana) and the Duch Guiana (currently Surinam). I understand that, although similar, each one of these histories keep important particularities. In the case of French Guiana, it brings for the attention the loss of French areas in Brazil, like in Rio de Janeiro (Antartica France) and in Maranhão (Equinocial France) as a strong motivation to choose this local, as well the subsequence difficult of population, illustrated by the Kourou tragedy.

Keywords: History, Politic, French Guiana, Amapá.

\section{INTRODUÇÃO}

A Guiana Francesa pode ser encarada enquanto uma região bastante peculiar. Único território sul-americano não independente, de fala francesa e população diminuta (cerca de 250 mil habitantes), faz fronteira com o Amapá e o Suriname, embora registre níveis de desenvolvimento social muito superior ao entorno. Se comparado a França, todavia, se mostra uma região pauperizada e subdesenvolvida, com também pouco espaço no plano simbólico, entre outras coisas, na própria historiografia de seu país (M AM LAM FOUCK, 2002, p. 11).

Não obstante essas estranhezas, a Guiana Francesa desenvolveu em seu passado 
interações dinâmicas, com ligações importantes com seus vizinhos. Com as subsequentes derrotas dos franceses no Rio de Janeiro e no $M$ aranhão, o litoral guianense converteu-se estratégico para sua metrópole no século XVII. Uma localização que franqueou a projeção para o norte da América do Sul e para o Caribe ao mesmo tempo.

Por outro lado, as dificuldades no tocante ao povoamento foram perenes, com tentativas de colonização em massa de europeus e busca de escravos na África e outras possessões no novo mundo. Como se a importância espacial e estratégica não conseguisse se traduzir em ocupação de fato e desenvolvimento econômico.

Tendo em vista esses impasses e contradições, pretendo neste artigo apresentar determinadas configurações que compuseram o passado da Guiana Francesa, com destaque para o período entre o início do século XVII até o início do século XIX. Seguindo esse escopo introdutório e necessariamente limitado, optei por uma exposição sintética e bastante ancorada em determinados autores, como Serge Mam Lam Fouck, infelizmente ainda indisponível em português.

\section{INÍCIO DA COLONIZAÇÃO}

O início da colonização francesa na Guiana seguiu a lógica conhecida da expansão comercial ultramarina europeia, com uma variável mais sublinhada que foi o caráter belicoso e militar em relação a demais potências colonizadoras da época. Em outras palavras, pesou nos motivos da chegada dos franceses ao continente sul-americano 0 fortalecimento da monarquia, a ideia de cristianização dos ameríndios e igualmente a competição política com as Províncias Unidas, Espanha, Portugal e Inglaterra.

Duas personagens centrais na história da França do período participaram ativamente da empresa. 0 cardeal Richelieu, conselheiro do rei Luís XIII entre 1624 e 1642, que incentivou o fortalecimento da marinha tendo em vista a expansão e conquista de novos domínios, e Jean Baptiste Colbert, Ministro de Estado de Luís XIV, vinte anos depois, que cristalizou na política econômica a necessidade de hegemonia francesa nas trocas comerciais internacionais, o que passava pelo controle de terras no novo mundo (M AM LAM FOUCK, 2002, p. 22).

A região das Guianas, logo batizada de "Costa Selvagem" pelos primeiros navegantes que por ali passaram, tendo em vista as robustas intempéries climáticas e geográficas, apresentou dificuldades de monta. O litoral entrecortado e de águas barrentas, fruto da influência, entre outras coisas, dos rios de água doce, dificultou a ancoragem de navios de grande calado. A ausência de uma população autóctone sedentária com estrutura de Estado reforçou a necessidade de guerras sucessivas para a manutenção do domínio. 0 clima equatorial inclemente, bastante díspar da metrópole, conjugado com a presença permanente de outras nacionalidades, como holandeses, portugueses e ingleses, num curto espaço, contribuiu para um ambiente de permanente desafio. As Guianas, não se pode olvidar, eram parte da América espanhola, segundo o tratado de 
Tordesilhas de 1492, contribuindo para o desinteresse dos portugueses (HYLES, 2014, p. 4).

M esmo a população ameríndia antes da chegada dos franceses nunca demonstrou um número elevado de contingente. Calcula-se em 30 mil os indivíduos que habitavam a Guiana, a chamada "civilização da mandioca", que não suportava uma população mais numerosa como a "civilização do arroz" do sudeste asiático (MAM LAM FOUCK, 2002, p. 20).

Em 1604, registrou-se a primeira expedição, comandada por um membro da nobreza de nome senhor de la Ravardière, que adentrou o rio Oiapoque, atual Amapá, e passou por Caiena, atual capital da Guiana Francesa. Personagem de suma importância para a época, o mesmo que fundaria oito anos depois no Maranhão a capital São Luís, homenagem a Luís XIII no contexto da França Equinocial, única capital na América portuguesa a não ser inaugurada pelos lusos.

Posteriormente, mais três tentativas infrutíferas de fixação foram levadas a cabo, nos anos de 1626, 1628 e 1630, cada uma contando com cerca de 50 pessoas e perecendo, frente às adversidades naturais e ao ataque de ameríndios e o assédio de outros povos europeus. Seguia-se a expulsão dos franceses do Maranhão, consumada em 1615, e suas tentativas de permanecerem na América do Sul. 0 nome também se repetiu, como projeto França Equinocial.

Em 1643, uma expedição diferente chegou ao local, patrocinada por uma companhia comercial privada, a chamada Companhia do Cabo Norte, e por comerciantes da região de Rouen. Comandada pelo senhor de Brétigny, essa empresa obteve a fixação de 400 pessoas, entre colonos e soldados. Cinco anos depois, em 1648, uma nova expedição foi enviada mas se desviou para o Caribe, percebendo que as Antilhas poderiam oferecer melhores condições de fixação e exploração econômica (op.cit., p. 23).

Em 1652, mais 800 colonos, entre eles 136 membros da nobreza, desembarcaram na Guiana, enfrentando um ataque severo de tribos ameríndias que ceifou a vida de metade dos recém chegados. Os que sobreviveram optaram por abandonar o lugar e se estabelecerem em Barbados. Nesse sentido, novo revertério ocorreu entre 1657 e 1665, quando os holandeses por sua vez ocuparam Caiena e expulsaram os franceses que ali residiam. 0 então ministro Colbert ordenou uma frota especialmente para a reconquista, que desembarcou em maio de 1665 e derrotou e de fato os holandeses, retomando o controle. 0 comandante da expedição bélica, Lefebvre de la Barre, fechou um tratado com os Galibis, reforçando sua posição e possibilitando a fundação de povoados ao redor de Caiena.

As guerras europeias atingiram em cheio o processo de ocupação. Em 1667, os franceses se tornaram aliados dos holandeses contra os ingleses, franqueando a esses últimos a expansão do conflito para a região. Assim, tomaram Caiena e a maioria dos povoados e se tornaram senhores da região, até perdê-los novamente para a Holanda em 1676. Finalmente, uma derradeira força militar francesa reconquistou as 
principais praças em dezembro de 1676, estabelecendo um status quo que duraria, grosso modo, até a invasão portuguesa de 1809. (M AM LAM FOUCK e ANAKESA, 2013, pp. 31-32).

Uma ocupação algo tardia, 176 anos após o estabelecimento de espanhóis e portugueses, e na esteira da penetração das nações não-ibéricas na América do Sul. Importante destacar que, semelhante a famosa definição de Frei Vicente do Salvador em relação aos portugueses no Brasil, "caranguejos arranhando o litoral", os franceses na Guiana também se limitaram a ocupação de uma faixa de terra restrita ao litoral, donde o interior e a ligação com a bacia amazônica permanecer nula naquele momento da história. Em 1700, uma estatística populacional apontava para a presença de 1.752 indivíduos, sendo 352 brancos, 1399 escravos, 11 libertos e 121 escravos índios (op.cit., p. 34).

Segundo Mam Lam Fouck (2002. P. 31),

Os franceses não estavam interessados na região das guianas senão por 0missão: era a região menos controlada dos vastos impérios espanhol e português; eles só se interessaram por alguns momentos em função do perigo da colonização francesa na América do Norte e nas Antilhas no século XVII e XVIII, na África e na Ásia nos séculos XIX e XX.

Destacou-se, naqueles primeiros momentos, a ação dos missionários voltados para a catequização dos ameríndios. Primeiro com os capuchinhos, a partir de 1651, e posteriormente com a maioria de jesuítas, especialistas nessa prática. Com efeito, reproduziram certas diretrizes espalhadas pelo restante da América ibérica, contribuindo para novo tipo de relação entre as populações nativas e os franceses que não a guerra aberta. Como a população indígena não chegou a se comparar em número com outros lugares, a escravização dos mesmos foi efêmera, em pequena escala e logo abandonada (HYLES, 2014, p. 56).

Embora com esse caráter secundários, a metrópole em muitos momentos bataIhou não só pela manutenção do espaço mas também pela sua expansão. Uma contradição entre a procura de terras e a falta de gente para seu efetivo uso. Por exemplo, em 1688, o tenente do rei, Pierre de Ferroles, partiu rumo aos domínios portugueses, chegando até o rio Araguari. Em 1697, alcançaram os fortes portugueses em Macapá, destruindo-os e sugerindo uma possível expansão das lindes guianesas. Esse movimento resultaria na disputa secular que iria até o final do XIX pelas Terras do Cabo Norte.

Com o contra-ataque português e a reconquista, a região se tornou em disputa militar, contemplada pelo Tratado de Utrecht de 1713, que encerrou momentaneamente a refrega atribuindo um limite mal definido entre os rios "Jupoc" / "Vicente Pinção". Cessaram as hostilidades militares em vista do combinado em estudos e delimitações para, através da diplomacia, estabelecer de direito o pertencimento da região (op.cit.). 
Igualmente a escravidão negra teve lugar nessas paragens, em quantidade bastante inferior em relação ao entorno regional. A responsabilidade pela importação de mão de obra africana escravizada na maioria do tempo esteve a cargo da Companhia Comercial da Guiana, que se transformaria, para gozar de uma abrangência maior, em Companhia do Senegal. "A Guiana recebeu somente uma ínfima parte do pujante fluxo de escravos africanos que atravessou o Atlântico entre o século XVII e XIX. Um século depois da introdução dos primeiros escravos, a colônia só contava com 5.728 (em 1765)" (M AM LAM FOUCK e ANAKESA, 2013, p. 37).

Diante dessa falta de trabalhadores, uma ideia foi delimitada pelo Barão de Bessner, por volta de 1782, consistindo em estabelecer tratados com os negros quilombolas (marrons) do Suriname para que viessem habitar a Guiana. Como não seriam escravizados, e sim contratados, causou espécie nos senhores de escravos plenos que temiam a contaminação ideológica desses "guerreiros do alto Marroni", podendo resultar na falência completa do sistema escravista. 0 projeto logo foi descartado. (op.cit., p. 38).

Dessas dificuldades resultou a implementação do mais ambicioso plano de colonização já concebido para a região. A importação de colonos brancos da Europa, sobretudo das regiões que hoje corresponderiam a parte ocidental da França e da época 0 que seria a Alemanha. Em 1763, quando esse plano passou a ser levado a sério, a colônia contava com 7.635 habitantes, sendo que o propósito seria importar 15 mil europeus. A ambição correspondia às necessidades múltiplas de defesa militar, produção de víveres e ocupação do espaço.

Assim, entre dezembro de 1764 e fevereiro de 1765, 9 mil pessoas desembarcaram na colônia, sendo outras 3 mil arregimentadas no decorrer dos meses subsequentes. A má-nutrição dentro dos navios e as intempéries de uma longa travessia fragilizou os corpos desses já pobres colonos do velho mundo. Chegando no sítio hoje conhecido como Kourou, a alimentação seguiu precária. Assim, "em alguns meses, a Guiana se transformou num necrotério. 0 paludismo, a febre amarela, febre tifoide, tifo, disenteria foram devastadores". De um total aproximado de 12 mil pessoas enviadas, 7 mil estavam mortas em outubro de 1765, 3 mil voltaram rapidamente e somente 1.800 escolheram permanecer. Uma verdadeira catástrofe, sendo que a maioria dos sobreviventes foi resgatada nas ilhas que ficariam conhecidas como Ilhas da Salvação (Iles Du Salut), posteriormente colonizando alguns lugares e dando origem a várias famílias de franco-guianenses que até hoje ali permanecem (op. cit. p. 39).

0 intendente Chanvalon, responsável pelo transporte e acomodação, foi preso. E 0 que chocou mais as autoridades da época aparentemente não foi tanto o número de mortes, uma vez que não era tão incomum milhares perecerem por epidemias devastadoras naquele período, senão o fato de tudo ter sido feito com logística, fundos e planejamento estatal. Esse episódio ficou conhecido como "expedição de Kourou", pois era para formar um grande povoamento nesse local, distante 60 quilômetros de Caiena. Foi a primeira e a última grande tentativa de povoamento do lugar, doravante marcado pela "síndrome de Kourou", isto é, um arrepio da espinha daqueles que 
tinham o destino marcado para habitar a Guiana. 0 escândalo desse morticínio atravessaria os próximos séculos (M AM LAM FOUCK, 2002, p. 52).

De modo que, no final do XVIII, já sob a Revolução Francesa, a alternativa encontrada para a ocupação da Guiana foi desafogar as prisões de Paris carregadas de encarcerados políticos e os enviarem para a Guiana. Entre 1795 e 1798, 331 pessoas foram desterradas da metrópole, o primeiro contingente de "banidos" que posteriormente cumulariam o lugar. Dessa primeira leva, 172 morreram, 25 escaparam e 132 conseguiram retornar para a França (op. cit. p. 40).

No momento da eclosão da Revolução já se havia fixado no imaginário popular a Guiana como um lugar de morte certa, a "guilhotina seca", daí ao mesmo tempo se mostrar um castigo severo para os revolucionários e um constrangimento do Estado de enviar pessoas para a reputada região infernal.

No que tange à economia propriamente dita, a Guiana Francesa tentou o cultivo em grande escala da cultura mais lucrativa da época, o açúcar, mas por falta de mão de obra não pode desenvolvê-la a contento. Os escravos africanos vendidos na região por franceses e piratas eram dirigidos para lugares mais lucrativos como as Guianas vizinhas, as Antilhas e o Caribe em geral. Na falta de colonos, juntava-se a falta de escravos, de índios escravizados e de interesse dos traficantes em frequentarem os portos. Um círculo vicioso negativo para as pretensões da exploração.

Comercializou-se o que estava ao alcance para tornar viável a empresa, e o grande produto adequado foi o "roucou" (anato), uma planta já conhecida dos ameríndios e que servia para a produção de corante, assemelhado ao pau-brasil das primeiras atividades econômicas europeias na América portuguesa (HYLES, 2014, p. 36).

Posteriormente se iniciou a produção de cacau, café e algodão. Segundo Mam Lam Fouck (2002, p. 42): "Aproximadamente 200 fazendas produziam anualmente, de 1776 a 1774, uma média de 376.700 libras de anato, 142.077 de algodão, 97.750 de cacau, 15.383 de açúcar e 38.697 de café". Números bem abaixo do que se produzia nas colônias francesas do Caribe, como Martinica, Guadalupe, e a porção de São Domingo.

Naquele contexto, além dos jesuítas, ameríndios e africanos escravizados, os habitantes da Guiana eram, com exceção das autoridades francesas, uma mistura de corsários, flibusteiros, piratas, marginais, protestantes que fugiam de perseguição e alguns judeus luso-brasileiros e holandeses. Uma mistura heteróclita que preocupava a administração.

No decorrer do tempo, a colônia foi sendo chefiada pelo governador, representante direto do rei, secundado por outras figuras como o tenente do rei, procurador geral, diretor do Interior e alguns outros: "Nos séculos XVII e XVIII o centro da vida política estava no Conselho Superior. Designado pelo governador entre os colonos mais ricos, ele possuía poderes em matéria de justiça e finança, além de zelar pela aplicação das ordens do rei" (M AM LAM FOUCK, 2002, p. 164).

A Revolução Francesa modificou esse cenário. Em agosto de 1790, foi eleita a pri- 
meira Assembleia Colonial, escolhida no seio da população branca independente da renda ou riqueza. Assim

sob a Revolução, os colonos autônomos se igualaram através da Assembleia Colonial ao governo da colônia durante dois anos (1790-1792). A Assembleia limitou os poderes do governador Bourgon, estabeleceu um diretório e um conselho administrativo que substituiu o poder de Estado; uma municipalidade criada em Caiena, e as tropas sendo alocadas sob o controle da Assembleia. 0 governador só retomou seus poderes com a chegada de comissários enviados de Paris (Idem, ibidem)

O Avanço democrático, a Assembleia foi boicotada pela classe dominante local, até ser abolida pelo próprio Napoleão Bonaparte alguns anos depois.

0 contexto também foi de abolição da escravidão, o que causou um profundo desequilíbrio nas relações de trabalho no local, mas também entre os vizinhos, sociedades firmemente escravistas. Na fase da Convenção, em 1794, foi levado a cabo a proibição do trabalho cativo em todas as colônias francesas. No território "Contestado", tendo o rio Araguari como divisa para os franceses e o Oiapoque para os portugueses, os escravos aproveitavam para construir seus quilombos e comerciar com as duas soberanias europeias. Na Guiana, ocorreu igualmente boicote da elite branca em cumprir as determinações revolucionárias. A abolição só perdurou até a cristalização do período napoleônico, em 1802 (HYLES, 2014, p. 59).

Em janeiro de 1809, uma tropa composta de luso-paraenses, com o apoio naval da marinha inglesa, conquistou a Guiana Francesa e a anexou a administração da Província do Grão Pará e Rio Negro. Tratou-se da culminação de aspirações internas articuladas com demandas externas. No primeiro caso, já circulava entre a classe dirigente paraense ideias de invasão dessa possessão francesa na América do Sul, como forma de eliminar a eterna ameaça da ocupação estrangeira sobre o território do Cabo Norte, afinal uma situação que reclamava complicados esforços de povoamento e defesa. No segundo, a invasão napoleônica em Portugal e a fuga da família real para o Brasil, findando com a declaração de guerra contra a França em junho de 1808, sugeria algum ato bélico contra Bonaparte que assertivamente demonstrasse o poder da corte lusa no exílio.

Desse modo, o príncipe regente Dom João ordenou ao governador da Província do Grão-Pará e Rio Negro, José Narciso Magalhães de Menezes, a constituição de uma força militar terrestre, que seria reforçada por dois vasos de guerra e contingentes do Rio de Janeiro mais uma embarcação comandada por ingleses. As dificuldades financeiras e logísticas não impediram a formação dessa tropa, que partiu de Belém em fins de 1808 rumo ao conflito.

A partir de janeiro do ano seguinte a Guiana Francesa tornou-se território português, ao menos provisoriamente, pois foi devolvida aos franceses em 1817, sem 0 recebimento de qualquer indenização, todavia com o estabelecimento dos limites 
geográficos que acabariam sendo novamente questionados com a independência de 1822 (CARDOSO, 2010, p. 14). Afinal os limites entre a Guiana e o Amapá continuariam em litígio até o laudo suíço de 1900.

Desse estranho desfecho muitas indagações foram apresentadas pelos historiadores, as principais girando em torno das diferentes percepções do problema entre 0 governo paraense, a administração na Corte e os militares ingleses. Grosso modo, para os primeiros importava anexar e projetar a colônia brasileira para o Caribe, protegendo o Cabo Norte e ao mesmo tempo abrindo maiores possibilidades de desenvolvimento econômico. Para a segunda, tratava-se mais de uma conquista a ser usada como barganha nas negociações de paz, tendo em vista muito mais a situação europeia do que a local. Para os terceiros, importava enfraquecer os franceses e ao mesmo tempo não permitir o crescimento territorial português, potencial ameaça as suas próprias possessões no entorno regional.

Não obstante, mesmo dentro dessas correntes havia percepções e aspirações contraditórias, o que demanda o estudo mais aprofundado do episódio. Além disso, os nove anos de domínio luso-paraense na Guiana também reclamam maiores cuidados analíticos devido a divergências de interpretação.

\section{CONSIDERAÇÕES FINAIS}

A Guiana Francesa se tornou um espaço de presença francesa no continente sulamericano após o fracasso das tentativas de estabelecimento nas terras já ocupadas pelos portugueses, mormente no Rio de Janeiro e no Maranhão.

M esmo assim, a ocupação não foi desprovida de conflitos, tanto com tropas portuguesas e espanholas quanto inglesas e holandesas. A posse definitiva de Caiena e a permanência de um núcleo de povoamento custou vidas e recursos materiais significativos.

Nos primeiros séculos extremas dificuldades acossaram os franceses em terras guianenses. A distância em relação a Paris e os problemas geográficos no tocante a correntes marítimas e portos seguros conspiraram para a rarefação de uma sociedade populosa. A resistência indígena, o clima e a disputa com outras potencias europeias pelo mesmo lugar contribuiu também para que a França privilegiasse outros lugares em detrimento do platô.

Tentou-se com a expedição de Kouru resolver esse problema de ocupação, e a tragédia advinda dessa empresa recrudesceu ainda mais as dificuldades e desconfianças no tocante a viabilidade da colonização. A Guiana Francesa, nesse sentido, sobreviveu pela sua importância estratégica militar, mais que econômica e política.

A defesa em relação a invasão portuguesa, por um lado, e a cobiça pelos territórios adjacentes, por outro, demonstrou a contradição entre uma condição periférica e de difícil administração com as possibilidades de uma possessão que poderia abrir caminhos para uma projeção mais estruturada e abrangente dos franceses na América do Sul. 


\section{REFERÊNCIAS}

CARDOSO, Ciro Flamarion. A Tomada de Caiena vista do lado Francês. In: Revista Navigator. Dossiê Tomada de Caiena. Rio de Janeiro, volume 6, número 11, 2010. pp. 13-23.

HYLE, Joshua. Guiana and The Shadows of Empire: Colonial and Cultural Negotiations at the Edge of the World. Londes: Lexington Books, 2014.

MAM LAM FOUCK, Serge. Histoire Générale de La Guyane Française. Matoury: Ibis Rouge, 2002

M AM LAM FOUCK, Serge; ANAKESA, Apollinaire. Nouvelle histoire de la Guyane: Des souverainetés amérindiennes aux mutations de la société contemporaine. Matoury: Ibis Rouge Editions, 2013.

Artigo recebido em 14 de setembro de 2016.

Aprovado em 13 de outubro de 2016. 